\title{
Design science research for decision support systems development: recent publication trends in the premier is journals
}

\author{
Shah Jahan Miah \\ College of Business \\ Victoria University \\ shah.miah@vu.edu.au
}

\author{
G. Michael McGrath \\ College of Business \\ Victoria University

\section{Don Kerr} \\ Faculty of Art and Business \\ University of the Sunshine Coast
}

\section{Abstract}

This paper presents a contemporary literature review of design science research (DSR) studies in the domain of decision support systems (DSS) development. The latest studies in the DSS design domain claim that DSR methodologies are the most popular design approach, but many details are still yet to be revealed for supporting this claim. In particular, it is important to thoroughly investigate the trends in either the form or deeper insights in use of DSR in this field. The aim of this study is to analyse the existing DSS design science studies to reveal insights into the use of DSR, so that we can outline research agenda for a special issue, based on findings of analysis. We selected articles (from 2005 to 2014) that were published in seven selected premier IS journals (ranked as A* in the ABDC journal ranking). The selected 57 sample articles are representative of DSS design studies that used DSR in theorising, designing, implementing, and evaluating DSS solutions. We discuss the theoretical positions of DSR for DSS development through six categories: DSS artefacts, DSR methods, DSR views, user involvement, DSS design innovations and problem domains. The findings indicate that new studies are needed to fill the knowledge gap in DSS design science, for more solid theoretical basis in near future.

Keywords: Design Science Research; DSS; Construction Centric Design Science; Human Centric Design Science; IS Research

\section{Introduction}

Decision support systems (DSS) development has been well-recognised research in Information Systems (IS) projects within the areas of unstructured, semi-structured and wellstructured problem domains. Vital explorations have been viewed in terms of technological developments in DSS such as using ontologies, human-centred techniques, simulations, data mining and business intelligence or analytic techniques. These approaches are designed to enhance the elicitation of decision problems and for designing effective support strategies (Haghighi, Burstein, Zaslavsky \& Arbon, 2013; Meensel, Lauwers, Kempen, Dessein \& Huylenbroeck, 2012; Mackrell, Kerr, \& von Helens, 2009; Miah, Kerr and Gammack, 2009; Miah, Ahsan and Msimangira, 2013). Despite this, few studies on the development of innovative IT systems (e.g. a DSS artefact) have explored the knowledge and understanding related to research methods needed for the design of such IT artefacts. In particular, existing research are still emergent activities to produce understanding and knowledge on how design methods such as design science research (DSR) could be used for an effective IT artefact design by presenting useful guidelines - addressing the combined requirements of technologies, people and organisations. This concern was raised in a recent study by Gregor and Hevner (2013) where it was argued that design research has yet to attain its full potential with respect 
to the effective development of various IS applications, as socio-technical systems. This is because there are gaps in the understanding and application of DSR knowledge and relevant concepts. We believe that this concern needs to be explored within the domain of DSS development.

Studies of DSS development have had a longhistory of utilising DSR patterns (Arnott \& Pervan, 2014, 2012). In one of their articles, Arnott and Pervan (2012) reported that of 1167 DSS research papers, 362 were classified as being concerned with DSS DSR studies. More recently, out of their analysis on 1466 DSS articles, Arnott and Pervan (2014) suggested that the seven years (from 2003 to 2010) of DSS research indicates a significant increase in DSS DSR to almost half of published articles, and that this represents a rapid transition in DSS research from a field based on statistical hypothesis testing and conceptual studies related to DSS solution design, into a new state, where DSR has evolved into a vital research method. This implies that the subject of DSR within DSS design studies is developing towards its maturity. It is therefore of paramount importance to investigate on DSR movements in DSS specifically on what forms of DSR methods have been developed and effectively utilised in guiding the design process of DSS artefacts over past IS studies.

Simon (1969) introduced the term design science by distinguishing it from natural sciences in his well-known book, The Sciences of the Artificial. Simon's work suggested that design sciences are established on how to design or construct IS solution artefacts (Hevner, March, Park and Ram, 2004). The work on the view of design science influenced IS researchers for the first time when Nunamaker and Chen (1990) and Nunamaker et al. (1991) outlined a new design methodology for developing effective IS artefacts. Subsequently, new ideas were brought together on how DSR could be theorised, redefined and actualised in the field of IS in order to achieve more effective understanding and design knowledge (Iivari 1991; Walls et al. 1992; March \& Smith, 1995). Building on existing work, Hevner et al. (2004) published the most-cited DSR framework (over 7,500 citations in Google scholar at J une 2016) published in MIS Quarterly, in order to provide a new shape of methodological understanding for conducting IS design research. Peffers et al. (2008) also proposed a DSR artefact design methodology that consists of six activity steps for conducting the IS design accomplishments. IS research has positioned itself between technology, organisational and managerial viewpoints (Carlsson, 2006; Orlikowshi \& Lacono, 2001) and a growing interest in design research is now evident in the global IS community (Vaishnavi \& Kuechler, 2007) and in operations research more widely (Manson, 2006).

A new view of DSR which is related to more holistic conceptualization of design has been offered by McKay, Marshall and Hirchheim (2012). In this, both behavioural and technical design components were recognized as being better for integration and for achieving improved design knowledge and understanding. Such conceptualization would identify beyond the need for DSR with the notions of product and function that well catered for in the guidelines of Hevner et al. (2004). The view described that there was a need for a focus on more immaterial notions such as systems, processes, organizations, user knowledge and experiences, on-going interactions, relationships and the situated meaning of things (McKay et al. 2012; Stewart 2011). McKay et al. (2012) suggested that there were problems with DSR orthodoxy and demonstrated the breadth of ways in which IS design could be conceived and, hence, the type of research that could be conducted. An argument was articulated suggesting that both construction-centric (CC) design (focusing largely on technical build-related activities) and human centric (HC) design perspectives - which placed emphasis on organization, people and the context of use) might together be better to inform IS design activities and achieve good result in research outcomes for more user-uptake. This suggests a clear requirement of practitioner oriented view of DSR that combines both views of CC and HC. This results in a collective design to promote active engagement of practitioners, for instance. Such a combined approach has been termed an ensemble artefact design view for DSS development (Miah and Gammack, 2014); it includes the content, context and processes (CCP) as defined by MacKrell and McDonald (2014). For instance, Miah, Gammack and Kerr (2007) introduced requirements of context-sensitive DSS design method that may better capture end-users' 
contextual realities. This reinforces us to explore on DSR in particularly for bringing more insights of DSR methods used in the existing DSS design literature.

In order to investigate the insights on use of DSR, we conducted a bibliometric content analysis adopted from Arnott and Pervan (2014). For the analysis we selected the seven premier IS journals in which DSS studies are most frequently published. The selected journals hold higher impact factors (we consider IF $>=2.33$ ) and were used for sample collection in the study by Arnott and Pervan (2014). From the journals, 57 sample papers were collected for our analysis. We attempted to answer the following questions.

- What are the particular types of DSR methods used in DSS design studies?

- What are the types of DSS artefacts designed in DSR studies for DSS design?

The results of this study promise to extend the use of DSR in DSS design further, to justify selecting this as a theoretical basis for the use of DSR approaches, and to identify further research directions for outlining a call for paper submission on a special issue in the particular - DSS DSR research domain.

This review paper is structured as follows: the next section describes the background of the study while the section 3 describes the methodological details. The section 4 presents the findings of the literature review and the section 5 describes the elected articles published in the special issue and further avenues of studies in the field. Finally, the section 6 provides a discussion and summarises the paper.

\section{Study Background}

DSS is well known class of IS applications that have a relatively long past as a major and rapidly growing research field within the IS discipline. DSS development research focuses on system development activities that help to identify, develop, innovate, implement, support and improve organisational, managerial, operational and other decision-making practices. The application of DSS development techniques covers various aspect of organisations and businesses; including, for example, public health (Walczak, Pofahl \& Scorpio, 2002), agriculture (Walker, 2002; Kerr, 2004; Miah, 2008), and finance (Muntermann, 2009). In a comprehensive literature review, Hosack, Hall, Paradice and Courtney (2012) suggested that DSS development research needed to shift its focus to the delivery of more "customer-centric" solutions. This implies that a significant research challenge still remains for DSS design, especially with DSS artefact design, to ensure that appropriate decision support features are available to provide adequate support for target stakeholders. The diversity of DSS artefact has been defined in four dimensions: construct, model, method and instantiation (Arnott \& Pervan, 2012). The analytical study by Arnott and Pervan (2012) called for immediate research attention to be directed towards DSS research design and its relevance to theory development for supporting more-useful DSS artefact designs.

Over the past recent decades, DSS has changed from a novel, cutting-edge (and somewhat inaccessible) technology to a point where advanced decision-making tools are now considered by many organisations to be essential components of their IS architectures (Arnott \& Pervan, 2012). While DSS has continued to grow as a significant area of IS, many studies attempted to employ and develop various development methodologies for meeting specific design needs. Classical DSS development methods such as user-centred approaches (Ayed et al. 2010), evolutionary prototyping and participatory approaches (Meensel et al. 2012) provide little support to system developers, especially on how to proceed with formal problem analysis and its conceptualization for producing views about the solution design. Arnott (2006) described the problem for a DSS developer; explicitly, how to conceptualize aspects of the decision task that need improvement during iterations of the evolutionary development process. Arnott and Pervan (2012) suggested that although many of the early DSS studies involved designing and implementing innovative IT artefact through classical development methodologies (for example, Keen \&Gambino, 1983), lack of user relevance and contextual reflections were found as common issues on their solution design. Hevner et al. (2004) exemplified growing interests 
on DSS design studies that indicate the success of the continuation in identifying and describing DSR in DSS research.

Although the DSR view shows promise over the classical approaches of IS development, the analysis of DSS DSR using Hevner et al.'s (2004) guidelines provides a basis for considering how to improve the quality and impact of DSS design studies(Arnott \& Pervan, 2012). As suggested, Arnott and Pervan (2012) indicated major five issues related to the research method ( $75 \%$ of previous DSS articles as being "weak" with respect to research methods), evaluation (42.3 \% 0f DSS articles did not undertake any form of evaluation), theorizing (the type of solution artefacts such as constructs, models, and methods - are considered as theory or components of theory). One of the strongest findings by Arnott and Pervan (2012) was that $66 \%$ of DSS artefacts are instantiations ${ }^{1}$, and have a strategic focus (Problem relevance, showed that $75 \%$ DSS articles have been focused on operational management problems). Arnott and Pervan (2012) also described how the fifth major issue, user relevance, cuts across the first four issues (research method, evaluation, theorizing, and strategic focus). The above issues identified and described by Arnott and Pervan (2012) indicated a major gap between DSS design research and practitioners' world of practices. As discussed above, the majority of DSS design is limited to developing problem solving techniques with the lack of adequate devotion at the practitioner's contextual demands; in most of the cases, the user involvement and their contextual relevance were ignored in order to develop newknowledge around the DSS solution artefact.

DSS development research has indicated the need to develop and employ more-rigorous methods for DSS solution development (Arnott \& Pervan, 2005, 2008, 2012; Miah, Kerr and von Helens, 2014; Miah and Gammack, 2014). This need can be addressed through a substantial exploration and improvement in design research. This may ensure for building understanding and knowledge around the quality and relevance in DSS development, by accommodating the system and its users and acknowledging the context of its use (such as the key components of technologies, people and organisations) (Miah et al., 2007, Miah, 2009). We argue that it is imperative for us to explore the full impact of design research for DSS development and reveal if there is a lack of proper utilisation, in "understanding of legitimate design research frameworks" and artefact design concepts when the DSS studies are attempted to capture relevant organisational needs (Hevner et al. 2004). To explore this issue we conducted a literature review to find the current status of the DSSDSR (that may lead to outline effective research agenda for publishing a special issue) such as to identify current portions of DSS studies that are using various forms of DSR such as CC, HC views, and contexts that have been highlighted. By doing this we should also have a better idea about why 75\% of DSS DSR is assessed as being weak with respect to the effective use of research methods.

\section{Methodology}

We utilised existing methodology for conducting our systematic literature review of studies on existing relevant DSS design. Kitchenham (2004) described the systematic literature review as a logical approach to identify, collect, evaluate and interpret information about current studies conducted in the target area of researchers' interest. For conducting a literature review, IS researchers have applied both qualitative and quantitative analyses by employing different methods. For example, Al-Debei and Avison (2010) used content analysis in their examination of a business model in the field of IS, while Arnott and Pervan (2012) explored the DSR for DSS research articles employing a specific type of content analysis method called "bibliometric" content analysis. Indulska and Recker (2010) also conducted qualitative content analysis on DSR articles to establish the claims of these articles on the usage of the DSR paradigm in IS research. In our study, we followed this same path for two purposes: 1) to

\footnotetext{
${ }^{1}$ March and Smith (1995) defined instantiation as a type of design artefact. This type of artefact represents full-functional application. The other types that are also described by many authors are model, method and construct (March and Smith, 1995; Hevner et al. 2004).
} 
analyse DSR methods for DSS development studies in previous research and 2) to identify DSS artefacts and solution development strategies in previous research.

We revisited published DSS DSR studies and examined the progress of the DSR in the DSS field from the year 2005 to 2014, for fulfilling our objectives specifically - the purpose of developing agenda of special issue. Figure 1 shows the overall procedure of our study reported in the paper. We found two main articles (such as Arnott and Pervan, 2014 and McKay et al. 2012) that provide us motivations for conducting the in-depth literature study in the area of DSS DSR. After that, we select a suitable approach for conducting the literature study. The bibliometric content analysis (Arnott \& Pervan 2014) was adopted to bring insights into our literature study, which comprised four phases: sample identification, sample study, sample analysis, and reporting outcomes. Bibliometric content analysis is a type of analysis that involves "coding and analysis of a representative sample of research articles" (Arnott \&Pervan, 2014, p.274). Theapproach provides a protocol for data capture that includes both quantitative and qualitative aspects. Applying both qualitative and quantitative analyses, we report the findings of the analysis to outline schema of the special issue and further research direction. Our analysis was focused on the following aspects:

- Does DSS research use construction or human-centric or context-specific DSR types?

- Do design studies ensure user involvement in the design and evaluation activities?

- What particular DSR method did they use?

- What aspect did the studies target in their DSS design innovation?

- What application areas did they use to build the DSS solution?

The answers provide us to come up with possible topic areas that may have potentials for new research, but we also focused on other relevant topics that were not limited to the prime areas - identified for publishing the special issue.

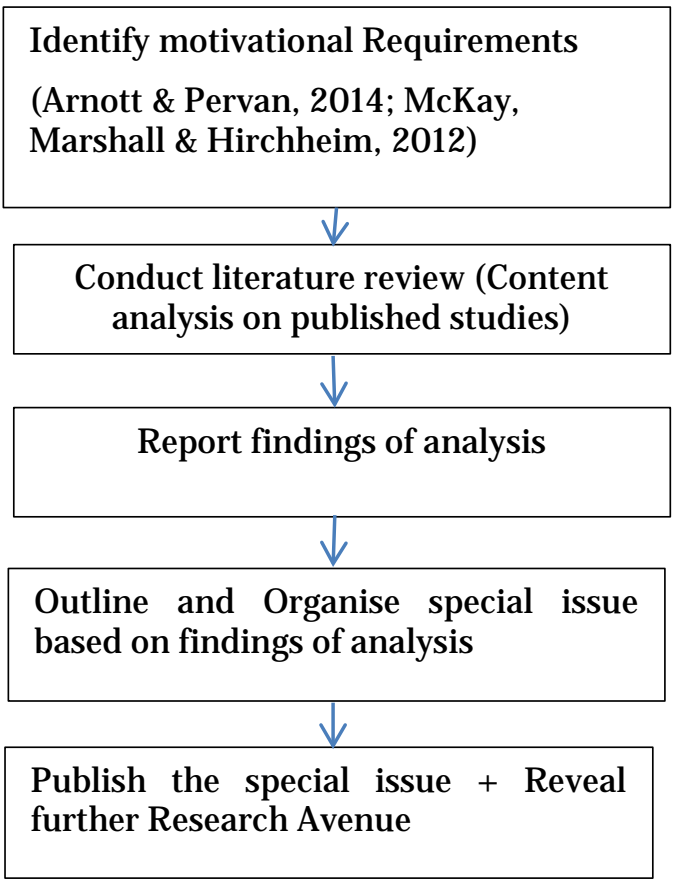

Figure 1: Overall procedure of our study reported in the paper

\subsection{Sources of text sampling}

Table 1 gives the list of journals from which we collected the sample articles (we refer as text sample) for our analysis. Our approach is different from the Arnott and Pervan (2014) 
methodology as we used a different set of rules in the sample identification phase, mainly for qualitatively analysing DSS development studies. We narrowed down the space for searching the text sample (articles), as we looked at published materials only in the premier IS journals listed by Arnott and Pervan (2014) that are listed in the latest ABDC (Australian Business Deans Council) journal ranking. We picked seven journals (out of 19 journals selected by Arnott and Pervan, 2014) that also hold higher impact factors - greater than 2.33 or above and frequently published DSS papers. The details of the selected journals are illustrated in Table 1. We searched samples published in these journals with the following keywords: "DSS and Design Science", "Design research" and "Decision support", "DSS" and "design science research", "Design studies" and "DSS", "design theory" and "DSS", "decision support systems" and "design science". The reason we chose journals from the list employed by Arnott and Pervan (2014) was to receive a validated and relevant sample of articles. However, more criteria were added to our process of selecting/ collecting DSS articles. These criteria were to focus on a) DSS papers that are fully designed and evaluated, b) design studies in DSS, c) the DSS design for individual's or managerial decision support rather than other forms of DSS, and d) DSS studies that discussed DSS design innovations leading to design theories. The rationale for applying these criteria was to gather relevant and reliable findings to meet the specific demands of our study. We finally identified 57 sample articles out of 116 initially found relevant through our manual selection process (in our sample selection phase - Table 2 illustrates the phases of text samples collection); this involved time consuming reading, so meaningful categories and/ or concepts on the sample could be developed for their selection or rejection (in our sample analysis phase).

\begin{tabular}{|l|c|c|c|c|}
\hline \multicolumn{1}{|c|}{ Journals } & $\begin{array}{c}\text { ACPHIS } \\
\text { Ranking }\end{array}$ & $\begin{array}{c}\text { IF: } \\
\text { Impact } \\
\text { Factors }\end{array}$ & $\begin{array}{c}\text { Arnott \& } \\
\text { Pervan, } \\
\text { (2014) DSS } \\
\text { Design } \\
\text { papers } \\
\text { (1990 to } \\
\mathbf{2 0 1 0 )}\end{array}$ & $\begin{array}{c}\text { Our review: No } \\
\text { of full- } \\
\text { functional DSS } \\
\text { DSR papers } \\
\text { (2005 to 2014) }\end{array}$ \\
\hline $\begin{array}{l}\text { Decision Support } \\
\text { Systems (DSS) }\end{array}$ & $\mathrm{A}^{*}$ & 2.331 & 41 & 44 \\
\hline $\begin{array}{l}\text { MIS Quarterly } \\
\text { (MISQ) }\end{array}$ & $\mathrm{A}^{*}$ & 7.497 & 7 & 2 \\
\hline $\begin{array}{l}\text { Decision Sciences } \\
\text { (DS) }\end{array}$ & $\mathrm{A}^{*}$ & 3.146 & 8 & 1 \\
\hline $\begin{array}{l}\text { Management } \\
\text { Science (MS) }\end{array}$ & $\mathrm{A}^{*}$ & 3.304 & 2 & 1 \\
\hline $\begin{array}{l}\text { Information and } \\
\text { Management (I\&M) }\end{array}$ & $\mathrm{A}^{*}$ & 3.796 & 10 & 1 \\
\hline $\begin{array}{l}\text { Information } \\
\text { Systems Research } \\
\text { (ISR) }\end{array}$ & $\mathrm{A}^{*}$ & 4.131 & 8 & 6 \\
\hline $\begin{array}{l}\text { Journal of } \\
\text { Information } \\
\text { Technology (J IT) }\end{array}$ & $\mathrm{A}^{*}$ & 3.000 & 5 & $\mathbf{5 7}$ \\
\hline Total: 7journals & & & $\mathbf{8 1}$ & 2 \\
\hline
\end{tabular}

Table 1: Selected journal details in which samples were collected 


\begin{tabular}{|l|c|c|l|}
\hline Steps & $\begin{array}{c}\text { Number } \\
\text { of text } \\
\text { samples } \\
\text { collected }\end{array}$ & $\begin{array}{c}\text { Number } \\
\text { of text } \\
\text { samples } \\
\text { selected } \\
\text { for the } \\
\text { analysis }\end{array}$ & \multicolumn{1}{|c|}{ Activities details } \\
\hline $\begin{array}{l}\text { Step 1: text sample } \\
\text { identification }\end{array}$ & 570 & 351 & $\begin{array}{l}\text { Initial Keyword searching } \\
\text { and checking }\end{array}$ \\
\hline $\begin{array}{l}\text { Step 2: text sample } \\
\text { selection }\end{array}$ & 351 & 127 & $\begin{array}{l}\text { Screening and reading } \\
\text { activities and }\end{array}$ \\
\hline $\begin{array}{l}\text { Step 3: text sample } \\
\text { Analysis }\end{array}$ & 116 & 57 & $\begin{array}{l}\text { Reading samples, and } \\
\text { manual acceptance } \quad \text { and }\end{array}$ \\
\hline $\begin{array}{l}\text { Step 4: Reporting on the } \\
\text { text samples }\end{array}$ & 57 & 57 & $\begin{array}{l}\text { Reporting, sorting } \\
\text { generalising aspects that are } \\
\text { of significance }\end{array}$ \\
\hline
\end{tabular}

Table 2: Process of our literature review

\subsection{Text sample analysis}

After identifying the text sample, we selected the most appropriate labels for the most relevant samples that qualified with our criteria. We focused on each sample one by one (for reading and note taking) and assigned a code that defined the artefact type, method used and design theory etc. After finishing the labelling, we commenced reading each article and taking notes on relevant aspects as part of the analysis tasks in the second round. The process was time consuming and laborious; sometimes, re-reading was required to re-adjust our initial observation. However, this helped us to gain greater insights into each text sample and on the categories that are shown below.

- $\quad$ DSS artefact types: March and Smith (1995) defined types of design artefacts as constructs, models, methods, and instantiations that are well-recognised in IS design research. Extending from this, Gregor \& Hevner (2013) described an additional outcome of DSR studies, which is 'design theory' (as "an abstract, coherent body of prescriptive knowledge" (Gregor \&Hevner, 2013, p. A3). A construct is a type of artefact that constitutes the problems specific language and solutions. A model is a type of artefact that uses the language to represent problems and solution. A method is a type of artefact that describes the processes and offers guidance on how to solve target problems. An instantiation is a type of artefact that explains problem-specific solution applications; that is, the aggregate of constructs, models, and methods (Miah \& Gammack, 2014; Hevner et al. 2004). The design theory is an abstract that explains prescriptive knowledge - describing the principles of form and function, methods, and justificatory theory that are used to develop an artefact (Gregor and J ones, 2007).

- $\quad$ DSR methods: The methods (e.g. the guidelines) of design research address the requirements of innovative design development, solution modelling or problem solving, as well as the evaluation of artefact design (Hevner et al. 2004; Carlsson, 2007).

- DSR views: We investigated on types of DSR views that were employed in design studies. McKay et al. (2012) described DSR views in terms of both construction-centric (CC) and human-centric (HC) design perspectives. The CC view is useful when the IT artefact and its relevant technical qualities are of interest to the DSR researcher. These artefacts may become of interest to the IS researcher working in the behavioural science paradigm. Such artefacts are seen as "surrounded" by human (e.g. user-specific problem context) and their contingencies called the HC view. McKay et al. (2012) also suggested that such artefact design may also place emphasis not only on technology and people, but also on the context of use and content of the design artefact. Such a 
view, which can represent the content, context and process together, might better inform design activities and result in research outcome that will achieve more practical uptake (Miah \&McKay, 2016).

- User involvement: "User participation" is often used interchangeably with "user involvement". Harris and Weistroffer (2009) described from Barki and Hartwick (1989) that the term "user participation" should be employed when referring to the behaviours and activities of the target users in the systems development process. Accordingly, "user involvement" has been referred to by Harris and Weistroffer (2009) as a psychological viewpoint of the individual user and has been defined as "the importance and personal relevance that users attach either to a particular system" (p.43) or to an IS design in general. We assessed how the user involvement were ensured in the phases or cycles of the DSS design studies.

- $\quad$ DSS design innovation aspect: Hevner et al. (2004) described how DSR pursues the production of innovations representing ideas, practices, technical capabilities, and products through which the analysis, design, implementation, management, and use of IS can be effectively and efficiently accomplished for addressing targeted issues. Therefore, it was important for us to assess on how the DSS design studies were transformed for offering value and quality into artefact design.

- Problem domain: Problem domain refers to the set of task structures under consideration in designing a solution. Some tasks of decision aids are people, process and product-focused issues. For instance, McKay et al. (2008) defined that it is important to describe organisational problems domain, in which DSR will concentrate on finding innovative and new solutions. Hevner et al. (2004) described a construct as an artefact that enables the construction of models or full representations of the problem domain. Such representation has a profound impact on the design of solution artefacts. We investigated different aspects of problem definitions that were defined in the DSS design studies.

\section{Findings}

Vital concerns of our text sample selection is that we found $77 \%$ of our samples of the DSS design studies published in DSS journal and rest of the 33\% of our text samples were from the other six IS journals. This indicates that Decision Support Systems journal is the only vital outlet, which published complete form (full-functional design articles) of DSS DSR over the past years. Other journals such as Journal of Information Technology also published some (lower proportions of) DSS DSR articles. However, we show a comparison in the study by Arnott and Pervan (2014) for validating such a sampling predisposition. Following Table 3 shows the findings of our literature analysis on DSS design studies. It suggested that about $65 \%$ of published DSS design studies used the CC view and about $14 \%$ of studies used the HC view of DSR methodology for developing innovative DSS artefacts. 


\begin{tabular}{|c|c|c|}
\hline Aspects & Findings & Comments \\
\hline DSS artefact types & $\begin{array}{l}\text { Construct as artefact }=1.7 \% \\
\text { Method as artefact }=49 \% \\
\text { Model as artefact }=28 \% \\
\text { Instantiation as artefact = } \\
15 \% \\
\text { Design theory as artefact = } \\
14 \%\end{array}$ & $\begin{array}{l}\text { The result represents the DSS design } \\
\text { artefact as a method of solution that was } \\
\text { vital in the past, while other types of } \\
\text { artefacts are still at embryonic stage in } \\
\text { development. }\end{array}$ \\
\hline DSR methods & $\begin{array}{l}\text { Hevner et al. } 2004=47.61 \% \\
\text { March and Smith, } 1995= \\
5.2 \% \\
\text { Peffers et al., } 2008=5.2 \% \\
\text { Others action research based } \\
\text { design studies = } 30 \%\end{array}$ & $\begin{array}{l}\text { The result shows that Hevner's seven } \\
\text { design principles, as design method, were } \\
\text { vital in use of DSS design while other } \\
\text { approaches such as the use of Peffers' } \\
\text { method looks still at the developmental } \\
\text { stage. Some DSS design studies (30\%) used } \\
\text { traditional approaches such as action- } \\
\text { research-based design studies. }\end{array}$ \\
\hline DSR views & $\begin{array}{l}\mathrm{CC}=65.52 \% \\
\text { Context specific }(\mathrm{HC}+\mathrm{CC})= \\
19.20 \% \\
\mathrm{HC}=14.02 \%\end{array}$ & $\begin{array}{l}\text { This shows that DSS design studies are } \\
\text { mainly based on the CC view and, therefore, } \\
\text { the practitioner's perspective in the design } \\
\text { may be ignored in most of the design cases. }\end{array}$ \\
\hline User involvement & $\begin{array}{l}\text { No: } 61 \% \text {; } \\
\text { Yes: } 34.10 \%\end{array}$ & $\begin{array}{l}\text { This shows that the majority of the studies } \\
\text { did not engage the user in the development } \\
\text { and evaluation processes. }\end{array}$ \\
\hline $\begin{array}{l}\text { DSS design } \\
\text { innovation aspect }\end{array}$ & $\begin{array}{l}\text { Higher = technical } \\
\text { capabilities oriented } \\
\text { innovations } \\
\text { Medium = Product oriented } \\
\text { innovations } \\
\text { Lower = ideas and practice- } \\
\text { oriented innovations }\end{array}$ & $\begin{array}{l}\text { This shows that the majority of the studies } \\
\text { did focus on technical improvement for } \\
\text { innovating artefact design to offer value } \\
\text { adding to user. }\end{array}$ \\
\hline Problem domains & $\begin{array}{l}\text { People-focused issue }=12 \\
\text { Process-focused issue }=27 \\
\text { Product-focused issue }=8\end{array}$ & $\begin{array}{l}\text { This shows that the majority of the studies } \\
\text { did on artefact design by innovating the } \\
\text { decision process improvement rather than } \\
\text { addressing product and people (user) } \\
\text { oriented issues }\end{array}$ \\
\hline
\end{tabular}

Table 3: Findings of the literature review, with comments on each aspect.

\section{Special Issues and Further Research Avenues}

From the aforementioned six aspects, we generalise three key areas of interest in which more studies are needed to fill the knowledge gap in DSS design science. The areas are DSS artefact design theory \& knowledge development (e.g. more HC related design theories), emerging \& innovative DSS artefact design (e.g. more problem and user specific DSS solution design and its diversified innovations), and DSS artefact evaluation (e.g. more theories on DSS evaluation - enhancement of direct user involvement). By advocating these issues, we generated a call for paper submission in a special issue in the Australasian J ournal of Information Systems (J une 2015). In total, eight articles have been submitted to this special issue. Two were declined as they were irrelevant to the main topic's area of interest. Therefore, only six articles qualified for the peer review process. After conducting three review cycles, only four articles were accepted for publication in the special issue. Key similarities of these studies are that each study ensured direct user involvement throughout their design research processes. The details of the published articles are given below.

Article 1: An Evaluation View of an Ensemble Artefact for Decision Support using Action Design Research (Dale MacKrell \& Craig McDonald)

This article represented an example of contemporary studies in DSS artefact evaluation research. The study investigated the integration of content, context and process (CCP) into the Action Design Research (ADR) framework to account for the interplay of organisational issues 
in artefact design and development. The investigation was conducted through a case study in which successive ICT student teams incrementally built, over several semesters, a tailored, low cost business intelligence system as an ensemble artefact for an organisation in the not-forprofit sector. During project development, CCP's human-centred approach to evaluation complemented ADR's more prescribed technology-driven software testing. The integration of CCP into ADR as an evaluation view offers a holistic approach to assessing an ensemble artefact. The resultant conceptual framework was presented as a model with an explication of unexpected design and research outcomes.

Article 2: Construction and Use of a 'Green Growth' Tourism Decision Support System: A Multi-Model Approach (G. Michael McGrath \& Geoffrey H. Lipman)

This article represented an example of innovative and emerging DSS artefact design study. The article describes a DSS artefact that was designed to support the development of "Green Growth" (GG) strategies for Travelism (Travel \& Tourism) destinations. A sound GG strategy is important: first, because tourism was a major contributor to the global economy particularly for developing and island states; second, because it represented some $5 \%$ of greenhouse gas (GHG) emissions and these are increasing faster than the global norm; and third, because the environment is an essential element of destination attractiveness. Thus, the problem domain is certainly non-trivial and important. The authors argued that the design of the DSS artefact described was original and novel in the sense that i) it supported the entire GG strategy development process (which is actually cyclical), ii) it allowed for the sharing of data, functionality and knowledge between different DSS applications and different strategy development exercises in a seamless, integrated manner, and iii) it will be deployed in a global community-based program in 2016. System design draws heavily on previous IS, information management and software engineering research, particularly with regard to use of abstraction and interfaces in support of component sharing and reuse.

Article 3: Development of a DSS and Online Tools to Support Sleep Disorder Consultations using Design Science (J acqueline Blake, Don Kerr \&J ohn Gammack)

This article represented another example of innovative and emerging DSS artefact design study. It also describes the use of design science to develop and evaluate a DSS incorporated into online tools to support a sleep physician's diagnosis of sleep disorders. The design science approach offers guidance for developing a solution that ensures i) that the artefacts fit into their usage context, and ii) that development and evaluation principles that generalise to similar problem domains are identified. How this project fits in the design science guidelines was specified, thus demonstrating how this philosophy and methodology advance theory, and are particularly relevant to other, similar medical diagnostic domains. The usability and technical evaluation of the set of tools indicated provide clear practical benefits at patient, physician and organisational levels.

Article 4: A Design Science Research Methodology for Expert Systems Development (Shah J Miah \& Hussein Genemo)

This article represented another example of innovative and emerging DSS (in the form of an expert system) artefact design study. The aim of this study was to investigate the use of DSR for ES design. First, we explored the ES development literature to reveal the presence of DSR as a research methodology. For this, the study selected relevant literature criteria and applied a qualitative content analysis in order to generate themes inductively to match the DSR components. Second, by utilising the findings of the comparison, the study determined a new DSR approach for designing a specific ES that is guided by another result - the findings of a content analysis of examination scripts in mathematics. The specific ES artefact for a case demonstration was designed for addressing the requirement of a "wicked" problem, in that the key purpose was to assist human assessors when evaluating multi-step question (MSQ) solutions. It is anticipated that the proposed design knowledge, in terms of both problem class and functions of ES artefacts, will help ES designers and researchers to address similar issues for designing information system solutions. 


\section{Overall Discussion}

We revealed three key areas of interest related to DSS design science studies that are of paramount importance for the field. As mentioned earlier these areas are: DSS artefact design knowledge, innovative DSS artefact design, and DSS artefact evaluation. These areas are emerging, but still limited for conducting more in-depth design studies on innovative and practitioners' centric DSS artefacts and their evaluation, as well as new knowledge and understanding growing on the emergent area of study. For example, future studies can explore how to build a DSS meta-artefact as a general solution concept to address any particular class of problems, such as Markus et al. (2002) developed a DSS theory for supporting emergent knowledge processes in problem domain. This type of research may offer benefits within the field. Although relevant DSR theories are introduced (e.g. Iivari, 2015) for the exploration of a meta-artefact in IS, appropriate investigation, application and modification of such approaches (only limited to Iivari, 2015) are yet to be undertaken within the domain of DSS design research. In addition, theories from previous empirical work in which DSR methods or strategies have been successfully applied can be an important aspect to develop in the form of new knowledge and that can be generalised as general solution concept (meta-artefact). In relation to research on DSS artefact evaluation, although studies (Phillips-Wren et al. 2009; Manyard, Burstein and Arnott, 2001) attempted to improve DSS evaluation strategies, there is a clear need for conducting research investigation in many aspects to better address and accomplish organisational and decision makers' behavioural issues that are vitally relevant for evaluating DSS artefacts.

Based on this analysis of the existing DSS design studies, we suggest that IS researchers should explore and conduct more new studies in the three directions. For instance, in order to enhance theoretical knowledge, studies can focus on generalising understanding of specific problem areas in which decision support applications are developed. This will enable researchers to employ, extend, revisit, and develop holistic DSR methods and frameworks for DSS. Researchers could pay more attention and do investigation to understand human and construction-centric views, and to better incorporating them when addressing context-specific realities. Coupled with the need for increasing technological flexibility in artefact design studies, and in order to re-adjust to rapidly changing user contextual and organisational factors, the range of DSS design methods and approaches can be outlined to meet both the demand of socio-technical and behavioural factors for appropriate artefact design and relevant knowledge creation. The need is imperative for conducting new DSS research that will enhance design knowledge and IS design approaches in the field. Further aims of research are articulated at supporting and recreating effective DSS design knowledge. The exploration of design knowledge will further establish the DSS field as a reference discipline.

\section{References}

Al-Debei, M. M. and Avison, D. (2010). Developing a unified framework of the business model concept, European J ournal of Information Systems, 19, 359-376.

Arnott, D. (2006). Cognitive Biases and Decision Support Systems Development: A Design Science Approach, Information Systems J ournal, 16 (1), 55- 78.

Arnott, D. and Pervan, G. (2005). A Critical Analysis of Decision Support Systems Research, J ournal of Information Technology, 20 (2), 67- 87.

Arnott, D. and Pervan, G. (2008). Eight Key Issues for the Decision Support Systems Discipline, Decision Support Systems, 44, 657- 672.

Arnott, D. and Pervan, G. (2012). Design Science in Decision Support Systems Research: An Assessment using the Hevner, March, Park, and Ram Guidelines, J ournal of the Association for Information Systems, 13 (11), 923-949.

Arnott, D. and Pervan, G. (2014). A critical analysis of decision support systems research revisited: the rise of design science, J ournal of Information Technology, 29, 269- 293 
Ayed, M., Ltifi, H., Kolski, C. and Alimi, A. (2010). A User-centered Approach for the Design and Implementation of KDD-based DSS: A case Study in the Healthcare Domain, Decision Support Systems, 50, 64- 78.

Barki, H. and J . Hartwick (1989). Rethinking the Concept of User Involvement, MIS Quarterly 13 (1), 53-63.

Carlsson, C. and Turban, E. (2002). DSS: directions for the next decade, Decision Support Systems, 33, 05- 110.

Carlsson, S.A. (2007). Developing Knowledge Through IS Design Science Research: For Whom, What Type of Knowledge, and How, Scandinavian Journal of Information Systems, 9(2), 75-86.

Creswell, J. W., Hanson, W. E., Clark Plano, V. L., and Morales, A. (2007). Qualitative Research Designs: Selection and Implementation, The Counselling Psychologist, 35(2), 236-264

Ellis, T. J ., and Levy, Y. (2008). Framework of problem-based research: A guide for novice researchers on the development of a research-worthy problem" Informing Science: International J ournal of an Emerging Transdiscipline, 11, 17-33.

Ercikan, K., and Roth, W.M. (2006). What good is polarizing research into qualitative and quantitative?, Educational researcher, 35(5), 14-23.

Fischer, A., Greiff, S., and Funke, J . (2012). The Process of Solving Complex Problems, The J ournal of Problem Solving, 4(1), 19-42

Giarratano, J. C., and Riley, G. (2005). Expert systems: principles and programming, Thomson Course Technology (4th ed), Cambridge, Mass.

Gregor, S. and Hevner, A.R. (2013). Positioning and Representing Design Science Research for Maximum Impact, MIS Quarterly, 37(2), 337-355

Gregor, S., and J ones, D. (2007). The Anatomy of a Design Theory, J ournal of the Association of Information Systems, 8(5), 312-335

Haghighi, P. D., Burstein, F., Zaslavsky, A. and Arbon, P. (2013). Development and evaluation of ontology for intelligent decision support in medical emergency management for mass gatherings, Decision Support Systems, 54, 1192- 1204.

Harris, M.A. and Weistroffer, H.R. (2009). A New Look at the Relationship between User Involvement in Systems Development and System Success," Communications of the Association for Information Systems, 24, 42. Available at: http:// aisel.aisnet.org/ cais/vol24/ iss1/ 42

Hevner, A., March, S., Park, J . and Ram, S. (2004). Design Science in Information Systems Research, MIS Quarterly, 28, 75- 105.

Hosack, B., Hall, D., Paradice, D. and Courtney, J.F. (2012). A Look Toward the Future: Decision Support Systems Research is Alive and Well, J ournal of the Association for Information Systems, 13, 315- 340.

Iivari, J., (1991). A paradigmatic analysis of contemporary schools of IS development, European J ournal of Information Systems, 1(4), 249- 272.

Iivari, J ., (2015). Distinguishing and contrasting two strategies for design science research, European J ournal of Information Systems, 24, 107- 115

Indulska, M. and Recker, J . (2010). Design Science In Is Research: A Literature Analysis. Information Systems Foundations, 285.

Keen P.G.W. and Gambino T.J., (1983). Building a Decision Support System: The Mythical Man Month Revisited, in J .L. Bennett (ed.), Building decision support systems, Reading, MA: AddisonWesley, 133-172. 
Kerr, D.V. (2004). Factors influencing the development and adoption of knowledge based decision support systems for small, owner operated rural businesses, Artificial Intelligence Review, 22 (2), 127-147.

Kitchenham, B., (2004). Procedures for Performing Systematic Reviews, J oint Technical Report, Keele University technical report TR/SE-0401, National ICT Australia Ltd, Garden Street, Eversleigh, NSW 1430, Australia Available at: http:// www.inf.ufsc.br/ aldo.vw/ kitchenham.pdf

Mackrell, D., Kerr, D.V. and von Helens, L. (2009). A qualitative case study of the adoption and use of an agricultural decision support system in the Australian cotton industry: the sociotechnical view, Decision Support Systems, 47,143- 153.

MacKrell, D. and McDonald, C. (2014). Incorporating content, context and process evaluation into action design research. Information Systems Foundation Workshop. The National Centre for Information Systems Research ANU.

Manyard, S., Burstein, F., and Arnott, D., (2001). A multi-faceted decision support system evaluation approach, J ournal of Decision Systems 10 (3-4), 395- 428.

March, S.T. and Smith, G.F., (1995). Design and natural science research on information technology, Decision Support Systems, 15, 251-266.

Markus, M. L, Majchrzak, A. and Gasser, L (2002). A design theory for systems that support emergent knowledge processes. MIS Quarterly, 26(3), 179-212.

McKay, J ., Marshall, P. and Hirchheim, R. (2012). The design construct in information systems design science, J ournal of Information Technology, 27, 125- 139

Meensel, J.V., Lauwers, L., Kempen, I., Dessein, J . and Huylenbroeck, G.V. (2012). Effect of aparticipatory approach on the successful development of agricultural decision support systems: The case of Pigs2win, Decision Support Systems 54, 164- 172.

Miah, S. J . (2008). An Ontology Based Design Environment for Rural Decision Support, Unpublished doctoral dissertation, Griffith University, Australia.

Miah, S. J . (2009). End user as application developer for decision support, Proceedings of the Americas Conference on Information Systems (AMCIS), 142. Retrieved 21 J uly, 2010 from: http:/ / aisel.aisnet.org/ amcis2009/ 142

Miah, S.J . and Gammack, J . (2014). Ensemble Artifact Design for Context Sensitive Decision Support, Australasian J ournal of Information Systems, 18 (2), 5-20.

Miah, S.J . and McKay, J . (2016). A New Conceptualisation of Design Science Research for Dss Development, Proceedings of the 20th Pacific Asia Conference on Information Systems (PACIS 2016), Taiwan.

Miah, S.J . Kerr, D. and von-Helens, L (2014). A collective artefact design of decision support systems: design science research perspective, Information Technology \&People, 27 (3), 259-279.

Miah, S.J., Ahsan, K., and Msimangira, KAB (2013). An Approach of Purchasing Decision Support in Healthcare Supply Chain Management, Operations and Supply Chain Management, 6 (2), 43-53

Miah, S.J., Gammack, J ., and Kerr, D. (2007). Ontology development for context-sensitive decision support, Proceedings of the Third International Conference on Semantics, Knowledge and Grid (SKG 2007), Xian, China, 475-478

Miah, S.J., Kerr, D. and Gammack, J. (2009). A Methodology to allow Rural Extension Professionals to build Target specific expert systems for Australian Rural Business Operators, Expert Systems with Applications, 36 (1), 735-744 
Muntermann, J . (2009). Towards ubiquitous information supply for individual investors: a decision support system design, Decision Support Systems, 47 (2), 82-92.

Nunamaker, J .F. and Chen, M. (1990). Systems development in information systems research, IEEE, 631-639.

Nunamaker, J .F., Chen, M., and Purdin, T.D.M. (1991). Systems Development in Information Systems Research, J ournal of Management Information Systems, 7(3), 89-106.

Orlikowski,W. J . and Iacono C. S. (2001). Desperately seeking the "IT" in IT research - a call to theorizing the IT artefact, Information Systems Research, 12 (2), 121-134

Peffers, K., Tuunanen, T., Rothenberger, M., and Chatterjee, S. (2008). A Design Science Research Methodology for Information Systems Research, J ournal of Management Information Systems, 24 (3), 45-77.

Phillips-Wren, G., Mora, M., Forgionne, G.A. and Gupta, J.N.D. (2009). An integrative evaluation framework for intelligent decision support systems, European J ournal of Operational Research 195, 642- 652

Simon, H. A. (1996). The Sciences of the Artificial (3rd ed.), MIT Press, Cambridge, MA.

Stewart, S. (2011). Interpreting Design Thinking, Design Studies, 32(6), 515- 520

Vaishnavi, V., and Kuechler, W. (2008). Design Science Research Methods and Patterns: Innovating Information and Communication Technology. Auerbach Publications, Boston, MA.

Venable, J . and Baskerville, R. (2012). Eating our own Cooking: Toward a More Rigorous Design Science of Research Methods, The Electronic J ournal of Business Research Methods, 10, 141-153.

Walczak, S., Pofahl, W.E., and Scorpio, R.J . (2002). A decision support tool for allocating hospital bed resources and determining required acuity of care, Decision Support Systems, 34, 445- 456.

Walker, H. (2002). Decision support, learning and rural resource management, Agricultural Systems, 73, 113- 127.

Walls J .G., Widmeyer, G.R. and EL Sawy, O.A. (1992). Building an information system design theory for vigilant EIS. Information Systems Research, 3(1), 36-59.

Copyright: (C) 2016 Miah, McGrath \& Kerr. This is an open-access article distributed under the terms of the Creative Commons Attribution-NonCommercial 3.0 Australia License, which permits non-commercial use, distribution, and reproduction in any medium, provided the original author and AJ IS are credited.

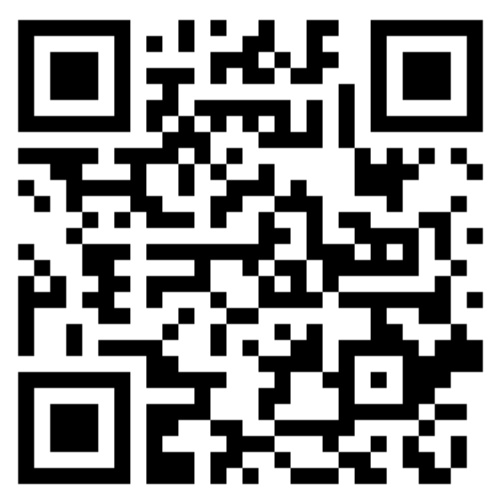

